Article

\title{
Poverty Suburbanization, Job Accessibility, and Employment Outcomes
}

\author{
Elizabeth Delmelle *, Isabelle Nilsson and Providence Adu \\ Department of Geography \& Earth Sciences, University of North Carolina - Charlotte, Charlotte, NC 28223, USA; \\ E-Mails: edelmell@uncc.edu (E.C.D.), inilsso1@uncc.edu (I.N.), padu@uncc.edu (P.A.) \\ * Corresponding author
}

Submitted: 8 October 2020 | Accepted: 4 December 2020 | Published: 13 May 2021

\begin{abstract}
The last decade of urbanization throughout many cities have seen a perceptible shift in the demand for centralized urban amenities while poverty has increasingly decentralized. Yet, the opportunity landscape of these shifting geographies of poverty and prosperity are not well understood. In this article, we examine how access to employment for low-income households has been impacted as a result of these changing geographies. Using a case study on the Charlotte metropolitan area we examine whether the suburbanization of poverty and reinvestment in the center city has reshaped the job opportunity landscape for low-wage residents. The objectives of this article are twofold. First, we calculate and map autobased accessibility from all neighborhoods in the Charlotte metropolitan area to job locations, differentiated by wage categories, in 2010 and 2017 to identify potential changes in the mismatch between low-income households and access to employment. We use a point-level employment dataset for these two years and calculate accessibility originating from census block groups. Second, we estimate the extent to which access to employment has affected employment rates and household incomes at the neighborhood level using a first-difference, spatial two-stage least squares model with instrumental variables. Our findings suggest that changes in accessibility had no significant effect on changes in neighborhood employment rates. However, we find evidence that increasing accessibility for lower-income households could have a positive effect on neighborhood median household incomes. Overall, the polycentric nature of Charlotte appears to have reduced the spatial mismatch between low-income workers and low-wage jobs.
\end{abstract}

\section{Keywords}

accessibility; labor market outcomes; income segregation; spatial dependence; spatial mismatch

\section{Issue}

This article is part of the issue "Vicious Circle of Segregation: Understanding the Connectedness of Spatial Inequality across Generations and Life Domains" edited by Tiit Tammaru (University of Tartu, Estonia), Siiri Silm (University of Tartu, Estonia), Frank Witlox (Ghent University, Belgium), Maarten van Ham (Delft University of Technology, The Netherlands) and Madli-Johanna Maidla (University of Tartu, Estonia).

(C) 2021 by the authors; licensee Cogitatio (Lisbon, Portugal). This article is licensed under a Creative Commons Attribution 4.0 International License (CC BY).

\section{Introduction}

In 1968, John Kain hypothesized that poor employment rates among inner-city African Americans were a result of the decentralization of employment and the inability of Blacks to relocate out of the inner-city, largely due to racial discrimination and segregation (Kain, 1968). This spatial mismatch hypothesis thus stated that unemployment was a direct result of limited physical access to employment opportunities. The hypothesis spurred a substantial research agenda that has tested whether access is related to employment outcomes, and has identified other important factors that may explain high unemployment rates such as lack of relevant skills, racial discrimination in hiring, or social networks, among others (Houston, 2005; Ihlanfeldt \& Sjoquist, 1990; Theys, Deschacht, Adriaenssens, \& Verhaest, 2019). The empirical evidence has generally shown a positive relationship between access and employment, especially to low-wage and entry-level employment (Allard \& 
Danziger, 2002; Bastiaanssen, Johnson, \& Lucas, 2020; Jin \& Paulsen, 2018; Mouw, 2000), but exceptions to this relationship exist and a consensus has yet to be reached for all income segments and all types of cities.

The bulk of our understanding of how job access is related to employment outcomes in the United States has occurred in the context of an urban America characterized by concentrations of racial segregation and economic disinvestment in center cities coupled with decentralizing employment. However, urbanization throughout many US cities-and in cities throughout the world-has undergone a perceptible shift in the demand for center-city amenities while poverty has increasingly decentralized (Raphael \& Stoll, 2010). Yet, the opportunity landscape for these shifting geographies of poverty and prosperity are not well understood.

The purpose of this article is to shed light on how the suburbanization of poverty and reinvestment in the center city have reshaped the job opportunity landscape for low-income residents using the rapidly growing metropolitan area of Charlotte, North Carolina, as a case study. We calculate changes in job accessibility between 2010 and 2017, differentiated by low and high-wage jobs and for low- and high-income population groups. We then estimate how changes in accessibility contribute to changes in unemployment levels and incomes at the Census block group level. Our findings suggest that changes in accessibility had no significant effect on changes in neighborhood employment rates. However, we find evidence that increasing accessibility for lower-income households could have a positive effect on neighborhood median household incomes. This may suggest that other factors such as skills gaps are relatively more important to improve opportunities for lower-income households, at least in metropolitan areas like Charlotte. Another possible explanation is that greater accessibility for lower-income households does not necessarily determine whether they are employed, but it offers a greater set of employment opportunities and hence the possibility of choosing a higher paying job.

\section{Background}

The spatial mismatch hypothesis was premised on the observation that employment was quickly suburbanizing as US cities decentralized alongside widespread highway and housing construction. At the same time, Blacks were largely restricted from moving to newer suburban neighborhoods due to a host of racial discriminatory practices. Thus, Black residents were increasingly physically separated from employment opportunities. Kain (1968) hypothesized that this distance was at least partially responsible for explaining high concentrations of unemployment among African American residents in central city locations. Over the past few decades, the stark poor and minority central city and white suburban dichotomy that described US cities of the 1960s has begun to change. The demand for urban amenities and accessibility has rejuvenated many urban cores, elevating property values, and forcing those unable to keep up with rising rents, to less-accessible, amenity deserts in older suburbs (Cooke \& Denton, 2015; Raphael \& Stoll, 2010). These shifting dynamics are not only the case for US cities-many European cities are contending with the same gentrification and poverty suburbanization forces as well (Bailey \& Minton, 2018; Hochstenbach \& Musterd, 2018). Thus, this 'Great Inversion' (Ehrenhalt, 2012) of sorting by income in cities calls for a re-evaluation of our understanding of (1) the spatial distribution of the low-income population, (2) the spatial distribution of low-wage jobs, and (3) the transportation infrastructure that connects them.

Theoretically, if the physical separation between poor residents and employment has been caused by center-city poverty and the suburbanization of jobs, then the movement of the poor towards the suburbs may prove favorable in diminishing this physical separation. On the other hand, businesses may also be relocating due to these shifting residential demands and an increased desire to be in central city locations. There are of course nuances to these relationships-lower-wage manufacturing jobs have decentralized more than service sector jobs that benefit from knowledge transfer and agglomeration effects (Glaeser \& Kahn, 2001). Some empirical studies have suggested that shifting urban dynamics including suburbanization are changing the job accessibility landscape $(\mathrm{Hu}, 2015)$ and that the suburban poor are at a disadvantage in terms of proximity to nearby jobs (Raphael \& Stoll, 2010).

The literature to date is largely in accordance that a greater separation between workers and jobs is a deterrent in finding employment, and that job access therefore impacts labor market outcomes-a finding that has held true across various continents including in US cities (Gobillon, Selod, \& Zenou, 2007; Ihlanfeldt \& Sjoquist, 1998; Theys et al., 2019), Europe (Matas, Raymond, \& Roig, 2010; Sari, 2015), and Latin America (Boisjoly, Moreno-Monroy, \& El-Geneidy, 2017). Both search and commuting costs increase with distance for residents and firms alike. A further distance also restricts information on potential job opportunities and likely excludes job seekers from critical social networks in finding opportunities (Ihlanfeldt \& Sjoquist, 1998). For low or minimum wage workers, commuting costs may quickly exceed pay, especially if the position is part-time (Sanchez, 1999). Given these mechanisms, the empirical evidence testing the relationship between job access and employment outcomes has largely yielded significant and positive results (Allard \& Danziger, 2002; Åslund, Östh, \& Zenou, 2010; Immergluck, 1998). However, some differences emerge on the magnitude and significance of this relationship when differentiating workers by income, suggesting that access may matter less for lower-income residents who tend to have worse employment outcomes despite higher levels of job access (Hu, 2017). A-spatial considerations that may deter lower-income 
workers from capitalizing on their location advantage include a mismatch in skills, networks, information (Ihlanfeldt \& Sjoquist, 1998; Stoll, 2005), or access to transit or an automobile (Grengs, 2010; Hu, 2017; Shen, 1998; Wang, 2003). Access to employment by transit appears to be an especially important consideration in cities outside of the United States (Matas et al., 2010; Sari, 2015).

Several more recent re-evaluations of this relationship point to the continued dichotomy in findings. Jin and Paulsen (2018) examined the effects of employment access on unemployment rates and household income, differentiated by income group and job sector for the city of Chicago. They found that increased access was associated with a decline in unemployment and an increase in median incomes among low-income households. They argue that prior studies that found contrasting results failed to account for the fact that labor market outcomes and residential location patterns are endogenous, and they correct this using an instrumental variable approach. Following that logic, Hu (2019) used a sub-sample of the Los Angeles population who had resided in their homes for a long time, and thus their residential location choices preceded employment decisions. For that polycentric city, access to jobs was insignificant in explaining employment for white and black job seekers, but it was significant for Hispanics and Asians. Clearly a consensus on the subject has yet to be reached and may vary by geographic context including urban form, employment sector composition, and residential segregation history. Chicago and Los Angeles are archetypical cities of contrasting urban form with Chicago largely following a monocentric and ordered spatial pattern to development and residential sorting, and Los Angeles the prototypical post-modern, polycentric, and auto-dominated city (Delmelle, 2019).

Our article contributes to this ongoing debate by examining the relationship between job access and labor market outcomes in a rapidly growing US Sunbelt city of Charlotte, North Carolina. We control for endogeneity following the approach outlined by Jin and Paulsen (2018) and segment between the income category of job seekers and the wage category of jobs.

\section{Data and Empirical Approach}

\subsection{Study Area and Data}

Our study area is the Charlotte-Concord-Gastonia Metropolitan Statistical Area (MSA) which consists of 10 counties in North Carolina (Mecklenburg, Union, Gaston, Cabarrus, Iredell, Rowan, and Lincoln counties) and South Carolina (York, Lancaster, and Chester counties). With a population of 2.569.213 (according to the American Community Survey [ACS] 1-year estimates in 2018) it is the largest metropolitan area in the Carolinas. The core city of Charlotte is one of the fastest growing cities in the US with a population of 872.498 , represent- ing a 18.6\% increase since 2010 (United States Census Bureau, 2020). However, its outlying towns have been growing at a faster pace partly due to rising costs of housing in the urban core (Chemtob \& Off, 2019). As the city has grown, it has seen an increase in the suburbanization of its poor population as well as job sprawl (Raphael \& Stoll, 2010). Charlotte is also battling economic mobility issues, as assessed by the likelihood that an individual born in the lowest income quartile will move to a higher quartile later in life. The city ranked last among the 50 largest US cities in this measure of upward mobility (Chetty, Hendren, Kline, \& Saez, 2014). In response to this, the Leading on Opportunity Council was formed in 2017 to address economic mobility issues in the city (Leading on Opportunity, 2020). Like many other places around the US, the Charlotte has experienced increasing poverty rates in the less dense parts of the MSA between 1990 and 2017 as seen in Figure 1.

The Charlotte MSA is not a monocentric city. Instead, employment and households are relatively spread out across the city of Charlotte and in its surrounding towns and cities (as will be further shown in Section 3.4). This is evident in Figure 2, which shows the location of spatial clusters of low-income households and low-wage sector jobs throughout the MSA in 2010 and 2017. The maps depict a Local Moran's I statistic (Anselin, 1995) on the count of low-wage jobs and low-income households. This statistic essentially compares the value jobs or households in a census block group and its adjacent block groups to the average for the entire metro. When a block group and surrounding neighborhoods are greater than the mean (and statistically significant), they are denoted as a 'high-high' cluster. When they are both statistically significantly lower than the average, they are indicated as 'low-low.' When a block group is higher than the mean, but its adjacent block groups are lower, it is denoted as 'high-low', and the reverse is true for 'low-high' symbols.

According to the figure, high-high concentrations of low-income households are present within the Charlotte beltway in the county in the center of the map (Mecklenburg). Between 2010 and 2017, the spatial expansion of high clusters of low-income households extends in a crescent within this loop-these neighborhoods are primarily older, low-density, first and secondring suburban neighborhoods. The concentration of housing constructed between the 1950s and 1960s in Charlotte proved to be a significant indicator of neighborhood socioeconomic decline between 2000 and 2010 (Delmelle \& Thill, 2014), and the pattern in the maps in Figure 2 suggest that this trend continued through the second decade as well.

As for lower-wage jobs, a rather major cluster can be found near the border, and crossing into neighboring South Carolina counties in 2010, a pattern that becomes more pronounced in 2017. Other high-high clusters of low-wage sector jobs are found in Iredell County to the north and Union County southeast of Mecklenburg County where Charlotte is the county seat. 


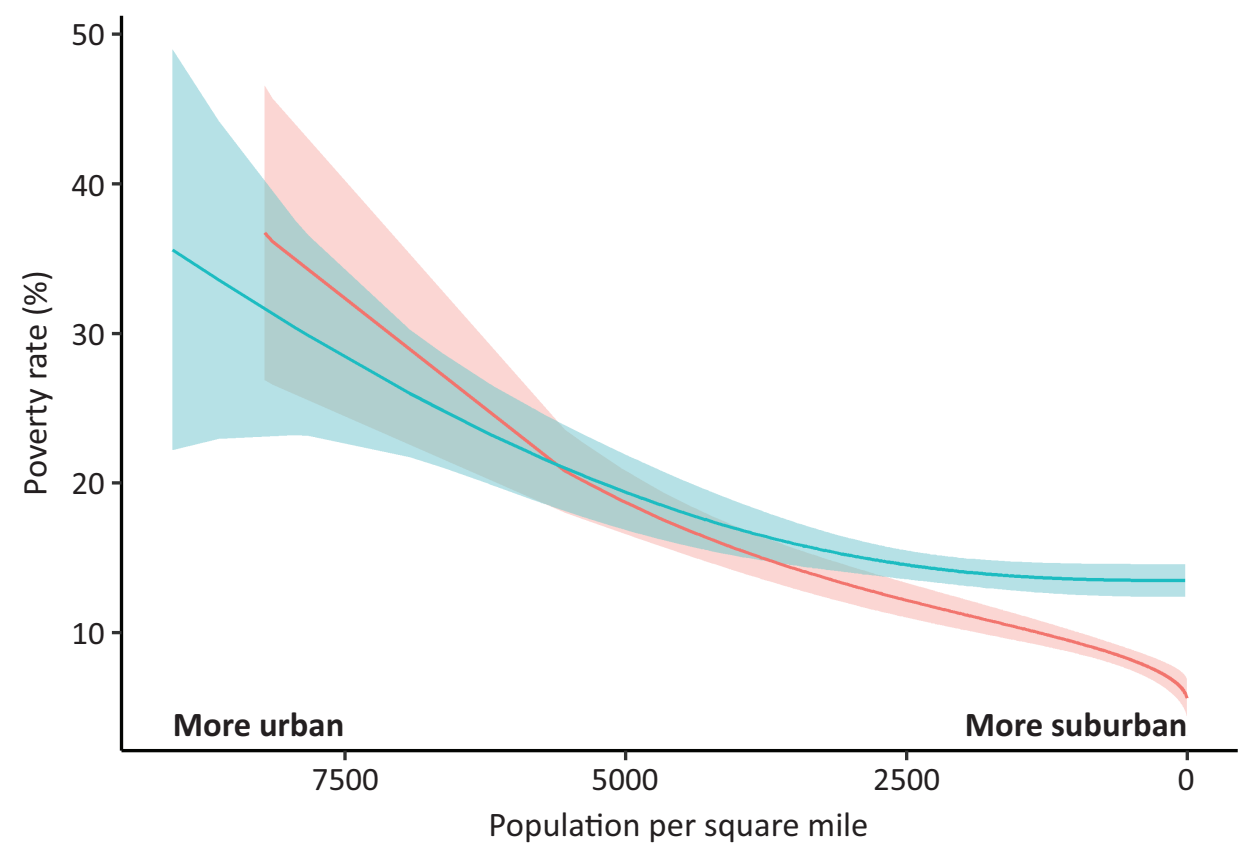

Year 1990 2017

Figure 1. Average census block group poverty rates with 95\% confidence bands vs. population density in 1990 and 2017.

Taken together, these maps paint a portrait of a polycentric city with low-wage and low-income households increasingly spread out away from the very center of the city's core. This dispersion away from the center does not create a visual appearance of an increased spatial mismatch between the two.

Socioeconomic and demographic data for this study comes from the ACS 5-year block group estimates which we use as point estimates for 2010 (2006-2010) and 2017 (2013-2017). Firm level job counts in 2010 and 2017 are obtained from InfoGroup's referenceUSA Historical Business database (referenceUSA, 2020). It includes the address of the business, number of employees, and its industry classification (NAICS codes). To obtain a proxy for the number of jobs at the block group level, we aggregate the number of employees in each two-digit NAICS sector by block group in 2010 and 2017, respectively. Hence, while employment rates, calculated as the number of employed over the total, noninstitutionalized, civilian population 16 years old and over, and other socio-economic and demographic variables by block group comes from the ACS block group estimates, job counts (or employment) is aggregated to the block group level from firm level employment data.

\subsection{Accessibility Measures}

To measure job accessibility, we apply the gravity model proposed by Shen (1998) and applied by Jin and Paulsen (2018) and $\mathrm{Hu}(2013,2015,2017)$. Merlin and $\mathrm{Hu}$ (2017) find a higher association between employment and accessibility when using Shen's approach as compared to accessibility metrics that do not incorporate competition. The metric is essentially a spatially weighted jobs to worker ratio as it considers the number of jobs in the numerator and job seekers in the denominator, both subject to a distance decay parameter. The model is specified as follows:

$$
A_{i}=\sum_{j} \frac{E_{j} e^{-\gamma d_{i j}}}{D_{j}}, D_{j}=\sum_{j} P_{k} e^{-\gamma d_{i j}}
$$

Where $A_{i}$ is accessibility of residents living in block group $i$. $E_{j}$ are the potential jobs in block group $i$ which is represented by job counts aggregated from firm level employment data, $\gamma$ is a distance decay parameter and $d_{i j}$ is the network-based drive-time between the origin and destination block group centroids. For this analysis, we only consider accessibility by car since the city of Charlotte and its surrounding area are auto-centric. The city of Charlotte, which has the most built out public transit system compared to other places in the MSA, $85.1 \%$ of workers commuted to work by car and only $2.8 \%$ by public transit according to 2018 ACS 1 -year estimates. $D_{j}$ is the demand potential in block group $j$. $P_{k}$ is the number of potential job seekers in location $k$ measured by the total working age population or the number of low- and high-income households, respectively, depending on the measure.

Using this formula, we calculate three different accessibility measures. First, we calculate an overall job accessibility index (ACC) which includes job counts in all industries and the working age population (16 years and over) in the civilian labor force in each block group. 


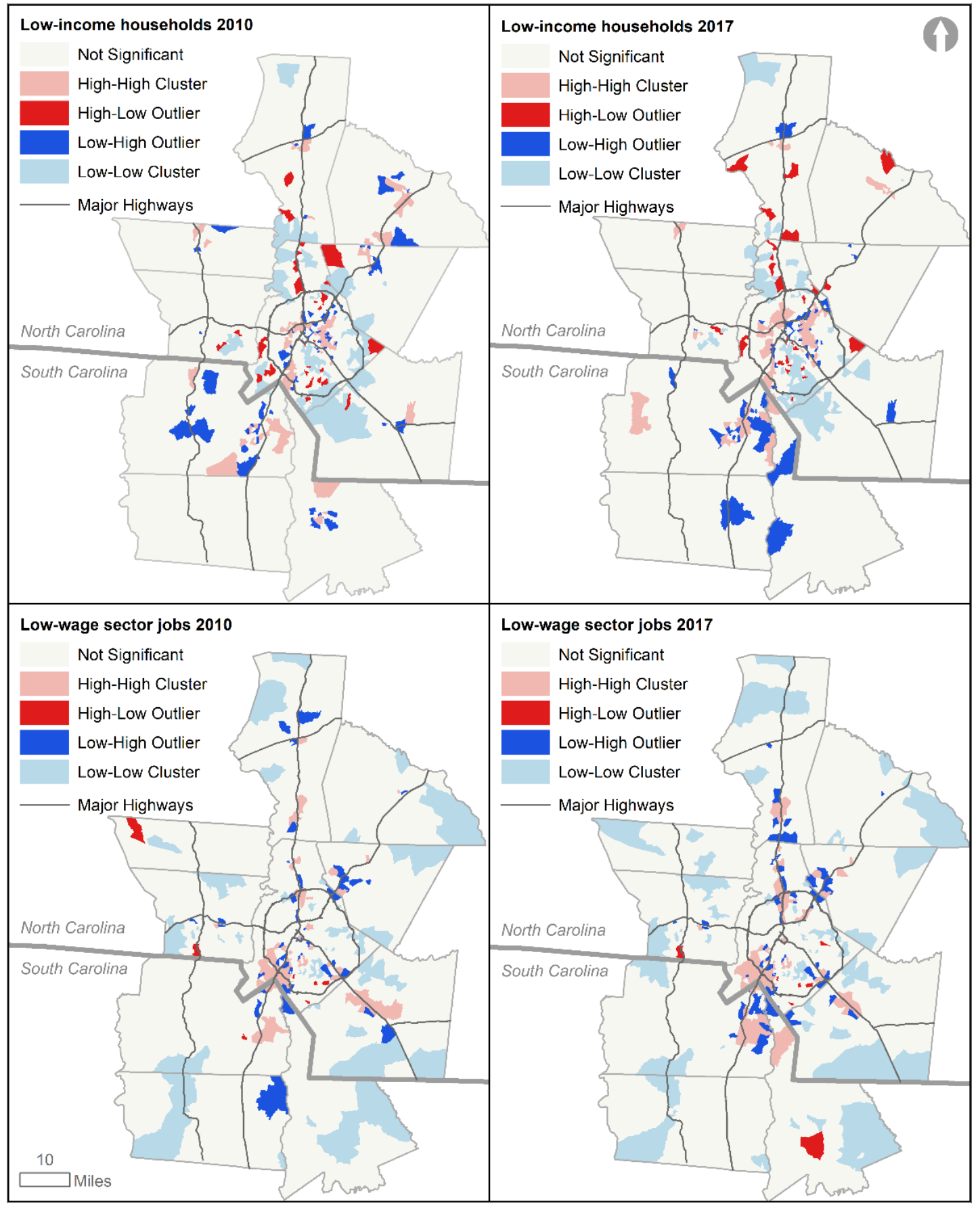

Figure 2. Local Moran's I clusters of low-income households and lower-wage jobs in 2010 and 2017, respectively.

Second, we construct an index for low-income households to jobs in sectors which are more likely to have entry-level or lower-skilled (hence lower-wage) positions available (ACC_LIH). These include Manufacturing (NAICS 31-33), Wholesale trade (42), Retail trade (44-45), and Accommodations \& food services (72). Finally, we calculate accessibility for high-income households to jobs in sectors which are more likely to have higher-skilled and higher-wage positions available (ACC_HIH). These include Information (NAICS 51), Finance and Insurance (NAICS 52), Professional, Scientific and Technical Services (NAICS 54), and Management of
Companies and Enterprises (NAICS 55). To define lowand high-income households, we use the definitions set out in the Home Mortgage Disclosure Act (HMDA) and the Community Reinvestment Act (CRA; see e-CFR, 2019 , section $228.12(m)$ ). Using this classification has the advantage of making the classification time and MSA specific. Low-income households are those whose income is less than $50 \%$ of MSA median household income and high-income are those with $120 \%$ or more of MSA median household income. The ACS data on number of households by income categories has 15 categories. We chose the income categories that come closest to 
matching the HMDA/CRA thresholds in each respective year.

Finally, for our distance-decay parameter, absent of empirical commuting data from which to estimate $\gamma$, we turn to other empirical estimates from the literature and test the sensitivity of our model on a range of values. Recently, Ding and Bagchi-Sen (2019) estimated commuting decay parameters by job sector for the city of Buffalo, New York. Their estimates ranged from 0.396 for lowincome workers to low-wage jobs to 0.4064 for all workers to all jobs. On the lower-end, Hu and Giuliano (2014) use a value of 0.1039 based on Los Angeles commuting flows. Other studies simply do not report which parameter they use (Jin \& Paulsen, 2018). We begin with the separate estimates by worker and wage category reported by Ding and Bagchi-Sen (2019), but also test the robustness of our model on values up to 1 and find no qualitative difference in our results.

\subsection{Empirical Model}

Since residential location is likely endogenous with other factors that influence labor market outcomes, we follow Jin and Paulsen (2018) and Mouw (2000) by estimating a first-difference, two-stage least squares model. This approach is applied to deal with various sources of potential endogeneity, including self-selection in residential location, reverse causality between labor market outcomes and job accessibility, neighborhood unobservables, and the relationship between household sorting by employment accessibility and income. In the first stage, the expected change in job accessibility of people living in neighborhood (block group) $i$ between 2010 and $2017, \widehat{\Delta A}_{i}$, is estimated on a set of instrumental variables and controls:

$$
\widehat{\Delta A}_{i}=f\left(D_{I S T M R}, D_{I S T S C}, \Delta \boldsymbol{X}_{i}\right)
$$

where $D I S T M R_{i}$ is the network distance from the centroid of block group $i$ to the nearest major road and DISTSC $i$ is the network distance to the centroid of the nearest employment subcenter, both in miles. The identification of employment subcenters are outlined in Section 3.4. $\boldsymbol{X}_{i}$ is a vector of neighborhood characteristics including changes in educational attainment, racial and income composition, population density, and average household size between 2010 and 2017 in block group $i$. While there is reason to believe that job accessibility is endogenous to labor market outcomes (Jin \& Paulsen, 2018; Mouw, 2000), we need to test the exogeneity of this regressor since ordinary least-squares (OLS) is consistent and more efficient than instrumental variable estimation if the potential endogenous regressor is exogenous (or weakly endogenous). To test the exogeneity of change in accessibility we apply the Hausman LM-test. Another important assumption of the instrumental variable approach is that the instruments are valid (or exogenous). To test for the exogeneity of the instruments, we apply the Sargan test on the validity of the instruments (Heij, Boer, Franses,
Kloek, \& Dijk, 2004). If change in accessibility is endogenous and its instruments valid, we regress the change in labor market outcomes (employment rates and median household income, separately) on the estimated change in job accessibility (from stage one) and neighborhood (block group) characteristics:

$$
\Delta L M O_{i}=\beta_{1} \widehat{\Delta A}_{i}+\beta^{\prime} \Delta \boldsymbol{X}_{i}+\Delta \varepsilon_{i}
$$

If change in accessibility is exogenous (or weakly endogenous) according to the tests, the model in Equation 3 is estimated using the actual change in accessibility $\left(\Delta A_{i}\right)$. Finally, there is reason to suspect that changes in labor market outcomes at the neighborhood level is spatially dependent given stronger interactions between nearby neighborhoods relative to more distant ones, and due to residential sorting and segregation by socioeconomic and demographic characteristics. Hence, we test the model in Equation 3 estimated using OLS for spatial autocorrelation in the residuals using Moran's I statistic. If there is evidence of spatial dependence, we estimate the model in Equation 3 as either a spatial lag model (Equation 4) or spatial error model (Equation 5), depending on the type of spatial dependence indicated by Lagrange Multiplier (LM) tests (Anselin, 1988). The spatial lag model is as follows:

$$
\Delta L M O=\rho W \Delta L M O+\beta_{1} \widehat{\Delta A}+\boldsymbol{\beta}^{\prime} \Delta \boldsymbol{X}+u
$$

where $W$ is a row-standardized, contiguity-based (Queen's case) spatial weights matrix, $\rho$ is a spatial autoregressive coefficient accounting for spatial dependence in the data generating process, and $u$ is a vector of residuals. The error model is specified as:

$$
\begin{gathered}
\Delta L M O=\beta_{1} \widehat{\Delta A}+\boldsymbol{\beta}^{\prime} \Delta \boldsymbol{X}+u \\
u=\lambda W u+\varepsilon
\end{gathered}
$$

where $\varepsilon$ is an independently but not necessarily identically distributed error term.

\subsection{Identification of Employment Subcenters}

To identify employment subcenters in the Charlotte MSA, we use the 2010 referenceUSA business establishment data and the 95\%-10K method introduced by Giuliano, Hou, Kang, and Shin (2015) and applied by Boarnet and Wang (2019). For this purpose, the Charlotte MSA is divided into 5,421 hexagons where each hexagon has an area of one square mile. Employment centers are defined as those hexagons with employment density greater than the 95th percentile of the entire MSA in year 2010, or 1.067 jobs per square mile. Subsequently, contiguous employment center hexagons are grouped together into candidate subcenters. Candidate subcenters with at least 10.000 jobs are identified as employment subcenters. This results in 12 employment subcenters in the Charlotte MSA which are shown in Figure 3. These subcenters consists of a total of 642.828 jobs, or $56.8 \%$ of the total number of jobs in the Charlotte 


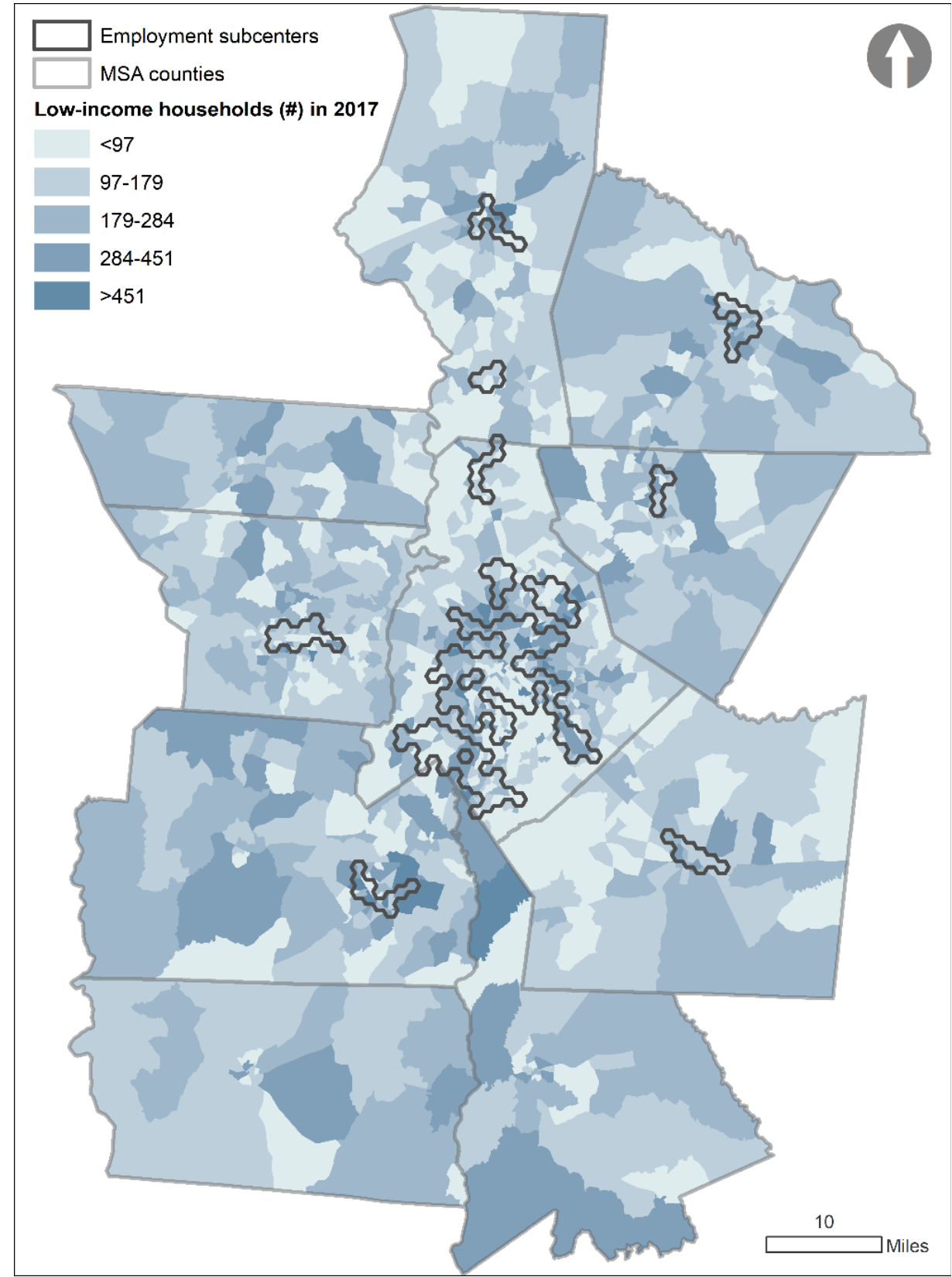

Figure 3. Employment subcenters in the Charlotte MSA.

metro region. As noted in Section 3.1, this shows the nonmonocentric nature of job locations in the Charlotte MSA with employment subcenters located in the bedroom communities to the urban center of Charlotte. The job composition in the subcenters versus the remaining MSA is quite similar. In 2017, the lower- versus higher-wage job split in the subcenters was $34 \% / 17 \%$ while this split in the remaining parts of the MSA was $35 \% / 10 \%$.

\section{Results}

Table 1 shows descriptive statistics for the variables used in the analysis. While one would expect employment rates to have increased on average between 2010 and 2017, recall that the employment rate is calcu- lated over the total (non-institutionalized civilian) population 16 years and older. In fact, unemployment rates have decreased on average by 1.88 percentage points. The explanation for this is likely that Charlotte has experienced a large population growth and, as noted by Graves and Kozar (2015), not at the same rate as the employment opportunities in the city. Hence, this has likely led to the denominator in the employment rate calculation to increase at a relatively faster than the numerator in many neighborhoods. Median household income on the other hand has risen by approximately $\$ 6,000$ on average. As for accessibility, overall accessibility and accessibility for higher-income households has reduced while accessibility for lower-income households has increased since 2010 , on average. 
Table 1. Descriptive statistics for census block groups.

\begin{tabular}{|c|c|c|}
\hline Variable & Meaning & Mean (sd) \\
\hline$\triangle \mathrm{ER}$ & Employment rates (\%) & $-0.54(10.71)$ \\
\hline$\triangle M E D H H I N C$ & Median household income $(\$ 1,000)$ & $6.00(16.48)$ \\
\hline$\triangle \mathrm{ACC}$ & Accessibility for population 16 years old and over in labor force to all jobs & $-0.31(5.16)$ \\
\hline$\triangle \mathrm{ACC} \_\mathrm{HIH}$ & Accessibility for high-income households to high-wage jobs & $-0.36(6.00)$ \\
\hline$\triangle \mathrm{ACC} \_$LIH & Accessibility for low-income households to low-wage jobs & $1.11(5.62)$ \\
\hline$\triangle \mathrm{BLACK}$ & Share of African American population (\%) & $0.76(11.73)$ \\
\hline$\triangle \mathrm{HIGHINC}$ & Share of high-income households (\%) & $4.71(11.61)$ \\
\hline$\triangle \mathrm{LOWINC}$ & Share of low-income households (\%) & $-2.47(12.82)$ \\
\hline$\triangle E D U C$ & Share of residents with at least a bachelor's degree (\%) & $3.35(10.21)$ \\
\hline$\triangle \mathrm{HHSIZE}$ & Average household size & $0.08(0.43)$ \\
\hline$\triangle P O P D E N$ & Population density (population per square mile) & $244.30(847.07)$ \\
\hline DISTMR & Distance to major road (miles) & $1.77(1.81)$ \\
\hline DISTSC & Distance to employment subcenter (miles) & $5.32(4.77)$ \\
\hline$N$ & & 1332 \\
\hline
\end{tabular}

Notes: All difference variables are indicted by $\Delta$ and refers to difference between year 2010 and 2017 . All changes in percentage variables are calculated as percentage point changes.

\subsection{Relationship between Job Access and Employment}

We now turn to the regression results for our first dependent variable: changes in employment rates at the block group level, following the Equation 3 and presented in Table 2. Overall, the three models (for all household, lowincome households, and high-income households) find that changes in accessibility have no significant impact on changes in employment rates.

As for model selection, the Hausman exogeneity test suggest that both the overall accessibility measure (ACC) and the accessibility measure for higher-income households (ACC_HIH) is endogenous with employment rates while the accessibility measure for lower-income households (ACC_LIL) is exogenous. The Sargan test cannot reject the null hypothesis of the instruments being exogenous (or valid) for the two models where change in accessibility was deemed endogenous. All three models show significant spatial autocorrelation in the residuals with the LM-test favoring spatial lag as best describing the spatial dependence structure. Therefore, the ACC and ACC_HIH models are estimated as two-stage least squares spatial lag models while ACC_LIL is estimated as a spatial model with the actual change in accessibility included.

While accessibility was not a significant predictor of employment, the estimated coefficients for other (statically significant) variables are as expected and robust across model specifications. For example, increases in education attainment has a positive effect on employment rates. Increases in the share of low-income or highincome households in the neighborhood is associated with a decrease or increase in employment rates. We also find that increases in the share of African American population in the neighborhood is associated with an increase in employment rates. Finally, the significant spatial autoregressive parameter suggests that block group employment rates are positively related to neighboring employment rates.

\subsection{Relationship between Job Access and Median Household Income}

For the models of median household income, presented in Table 3, we do find a significant, positive relationship between accessibility and neighborhood median income in the case of low-income households (ACC_LIH). In this case, we find that increasing accessibility for lower-income households could have a positive effect on neighborhood median household incomes, but this same effect is not found for the overall model or for higherincome households.

With respect to model selection for this dependent variable, the Hausman exogeneity test suggest that the different accessibility measures are exogenous. Hence all three models are estimated with the non-instrumented change in accessibility. Moran's I and the LM-tests suggests that the ACC and ACC_HIH models should be estimated as spatial error models while the ACC_LIH model shows no significant spatial autocorrelation in the residuals and is therefore estimated using OLS. Aside from accessibility, other independent variables are similar to those of the employment rate model with increases in educational attainment and share of high-income household having a positive effect on neighborhood median household income. As expected, an increase in the share of low-income households is associated with a decrease in median household income. We find some weak evi- 
Table 2. Estimation results for changes in employment rates using spatial lag.

\begin{tabular}{|c|c|c|c|}
\hline Variable & ACC (lag, 2SLS) & ACC_LIH (lag) & ACC_HIH (lag, 2SLS) \\
\hline$\triangle \mathrm{BLACK}$ & $\begin{array}{l}0.061 * * * \\
(0.022)\end{array}$ & $\begin{array}{l}0.061^{* * *} \\
(0.022)\end{array}$ & $\begin{array}{l}0.061 * * * \\
(0.023)\end{array}$ \\
\hline$\triangle \mathrm{HIGHINC}$ & $\begin{array}{l}0.126^{* * *} \\
(0.025)\end{array}$ & $\begin{array}{l}0.125^{* * *} \\
(0.024)\end{array}$ & $\begin{array}{l}0.127^{* * *} \\
(0.025)\end{array}$ \\
\hline$\triangle$ LOWINC & $\begin{array}{l}-0.269 * * * \\
(0.023)\end{array}$ & $\begin{array}{l}-0.271 * * * \\
(0.022)\end{array}$ & $\begin{array}{c}-0.270 * * * \\
(0.023)\end{array}$ \\
\hline$\triangle \mathrm{EDUC}$ & $\begin{array}{l}0.088^{* * *} \\
(0.027)\end{array}$ & $\begin{array}{l}0.089 * * * \\
(0.027)\end{array}$ & $\begin{array}{l}0.087^{* * *} \\
(0.027)\end{array}$ \\
\hline$\triangle \mathrm{HHSIZE}$ & $\begin{array}{c}-1.228^{*} \\
(0.654)\end{array}$ & $\begin{array}{c}-1.229 * \\
(0.651)\end{array}$ & $\begin{array}{c}-1.216^{*} \\
(0.654)\end{array}$ \\
\hline$\triangle$ POPDEN & $\begin{array}{c}0.000 \\
(0.000)\end{array}$ & $\begin{array}{c}0.000 \\
(0.000)\end{array}$ & $\begin{array}{c}0.000 \\
(0.000)\end{array}$ \\
\hline$\triangle \mathrm{ACC}$ & $\begin{array}{c}0.014 \\
(0.130)\end{array}$ & & \\
\hline$\triangle \mathrm{ACC}$ LIH & & $\begin{array}{c}-0.030 \\
(0.047)\end{array}$ & \\
\hline$\triangle \mathrm{ACC} \_\mathrm{HIH}$ & & & $\begin{array}{c}0.039 \\
(0.118)\end{array}$ \\
\hline Constant & $\begin{array}{l}-1.858^{* * *} \\
(0.305)\end{array}$ & $\begin{array}{c}-1.868 * * * \\
(0.308)\end{array}$ & $\begin{array}{c}-1.852^{* * *} \\
(0.305)\end{array}$ \\
\hline$\rho$ & $\begin{array}{l}0.381^{* * *} \\
(0.095)\end{array}$ & $\begin{array}{l}0.318^{* * *} \\
(0.100)\end{array}$ & $\begin{array}{l}0.382 * * * \\
(0.095)\end{array}$ \\
\hline$N$ & 1352 & 1352 & 1352 \\
\hline Pseudo $\mathrm{R}^{2}$ & 0.180 & 0.182 & 0.181 \\
\hline Hausman test & $12.698 * * *$ & 0.679 & $5.957^{* *}$ \\
\hline Sargan test & 0.002 & $11.319 * * *$ & 1.644 \\
\hline Moran's I (residuals OLS) & $1.854^{*}$ & $2.318^{* *}$ & $2.173 * *$ \\
\hline LM (lag) & $4.914^{* *}$ & $7.662 * * *$ & $6.340 * * *$ \\
\hline LM (error) & $3.066^{*}$ & $5.034 * *$ & $4.253^{* *}$ \\
\hline
\end{tabular}

Notes: ${ }^{* *}, * *$, and $*$ denotes statistical significance at $1 \%, 5 \%$, and $10 \%$; standard errors in parentheses.

dence that increasing population density is associated with increasing median household incomes. This could be attributed to the rebirth of the Charlotte center-city and its surrounding neighborhoods.

\section{Conclusion}

The debate surrounding the impact of accessibility on labor market outcomes first proposed by Kain (1968) has yet to be settled-issues of measurement and model specification have yielded contrasting resultsand the urban landscape initial described by Kain (1969) has undergone dramatic transformations across many cities. In this study, we re-examine this relationship in the rapidly growing, southern city of Charlotte, North Carolina, and its encompassing metropolitan area. Charlotte's dynamics have featured both strong greenfield suburbanization and center-city revitalization and gentrification, while poverty has increasingly shifted towards older, first-ring suburbs. However, job locations, especially lower-income jobs, are relatively spread out across the Charlotte MSA and clusters of low-wage jobs and lower-income households often coincide in space. Within this context, we estimated how changes in accessibility at the block group level impacted changes in employment rates and median household incomes between 2010 and 2017. We controlled for the potential endogeneity of residential location choices and labor market outcomes using the two-stage instrumental variable approach proposed by Jin and Paulson (2017) and also account for spatial dependence in our model specification where appropriate. We differentiated our models between low- and high-wage workers and low- and high-skilled jobs.

Our results suggest that changes in job accessibility had no significant impact in changes in neighborhood employment rates. This is likely explained by the relatively close distribution of lower-wage jobs and 
Table 3. Estimation results for changes in median household income (\$) using spatial error and OLS.

\begin{tabular}{|c|c|c|c|}
\hline Variable & ACC (error) & ACC_LIH (OLS) & ACC_HIH (error) \\
\hline$\triangle \mathrm{BLACK}$ & $\begin{array}{c}1.308 \\
(34.468)\end{array}$ & $\begin{array}{c}-7.431 \\
(34.333)\end{array}$ & $\begin{array}{c}-1.516 \\
(34.525)\end{array}$ \\
\hline$\triangle \mathrm{HIGHINC}$ & $\begin{array}{l}661.888 * * * \\
(38.008)\end{array}$ & $\begin{array}{l}668.276^{* * *} \\
(38.068)\end{array}$ & $\begin{array}{l}661.210 * * * \\
(38.053)\end{array}$ \\
\hline$\triangle \mathrm{LOWINC}$ & $\begin{array}{c}-388.892^{* * *} \\
(34.652)\end{array}$ & $\begin{array}{c}-379.806^{* * *} \\
(34.730)\end{array}$ & $\begin{array}{c}-392.809 * * * \\
(34.601)\end{array}$ \\
\hline$\triangle \mathrm{EDUC}$ & $\begin{array}{l}145.601 * * * \\
(41.187)\end{array}$ & $\begin{array}{l}158.137^{* * *} \\
(41.208)\end{array}$ & $\begin{array}{l}146.722 * * * \\
(41.192)\end{array}$ \\
\hline$\triangle \mathrm{HHSIZE}$ & $\begin{array}{c}1757.473^{*} \\
(993.291)\end{array}$ & $\begin{array}{l}1432.462 \\
(993.478)\end{array}$ & $\begin{array}{l}1802.062 * \\
(993.943)\end{array}$ \\
\hline$\triangle P O P D E N$ & $\begin{array}{c}0.704 \\
(0.495)\end{array}$ & $\begin{array}{l}0.978 * * \\
(0.485)\end{array}$ & $\begin{array}{c}0.787^{*} \\
(0.491)\end{array}$ \\
\hline$\triangle \mathrm{ACC}$ & $\begin{array}{r}-101.362 \\
(81.348)\end{array}$ & & \\
\hline$\triangle \mathrm{ACC}$ LIIH & & $\begin{array}{l}240.859 * * * \\
(71.943)\end{array}$ & \\
\hline$\triangle \mathrm{ACC} \_\mathrm{HIH}$ & & & $\begin{array}{c}-3.950 \\
(68.205)\end{array}$ \\
\hline Constant & $\begin{array}{c}-6.891 \\
(486.523)\end{array}$ & $\begin{array}{r}-312.354 \\
(460.085)\end{array}$ & $\begin{array}{c}-8.481 \\
(489.310)\end{array}$ \\
\hline$\lambda$ & $\begin{array}{l}0.089 * * \\
(0.044)\end{array}$ & & $\begin{array}{l}0.096 * * \\
(0.044)\end{array}$ \\
\hline$N$ & 1352 & 1352 & 1352 \\
\hline Pseudo $\mathrm{R}^{2}$ & 0.380 & 0.384 & 0.379 \\
\hline Hausman test & 1.172 & 2.152 & 0.457 \\
\hline Sargan test & 1.521 & 1.875 & $3.857^{* *}$ \\
\hline Moran's I (residuals OLS) & $1.860 *$ & 1.409 & $1.993 * *$ \\
\hline LM (lag) & $2.732^{*}$ & 2.128 & $3.142^{*}$ \\
\hline LM (error) & $3.180 *$ & 1.792 & $3.693 * *$ \\
\hline
\end{tabular}

Notes: ${ }^{* *}, * *$, and $*$ denotes statistical significance at $1 \%, 5 \%$, and $10 \%$; standard errors in parentheses.

lower-income households in the Charlotte MSA. In other words, the spatial separation between lower-wage workers and their workplaces is already relatively small. However, we found that increased accessibility for lowerincome households was associated with higher median incomes. One possible explanation for these results is that accessibility does not necessarily have an influence on whether or not low-income households obtain employment, but greater accessibility does lead to a greater set of employment opportunities to choose from and hence the possibility of choosing a higher paying job.

Our results contrast those of Jin and Paulson (2017) for the city of Chicago who did find a positive relationship between access and labor market outcomes. However, they are consistent with Hu's (2019) analysis for Los Angeles. In a prior study, Hu (2015) similarly found that the dynamics of poverty suburbanization in Los Angeles served to mitigate the spatial mismatch between low-income residents and employment oppor- tunities. Collectively these differences may be ascribed to contrasts in urban structure-Charlotte is more akin to the polycentric nature of Los Angeles as compared to the more monocentric Chicago. Together, these results suggest that a more polycentric city-structure could potentially mitigate spatial mismatch. Though more comparative analyses are needed, our analysis adds a piece of evidence to this debate.

Like $\mathrm{Hu}$ (2015), we do not find support for the argument that access to jobs is a barrier to employment among lower-income residents, and thus other non-spatial factors and policies are likely to be more successful in lowering unemployment rates. However, our finding on the relationship between access and income could prove beneficial in ameliorating some of the upward economic mobility problems faced by Charlotte's lowest-income residents (Chetty et al., 2014). Future research should further probe the hypothesis that access to a larger number of employment opportunities 
does indeed result in increased wages among lowerincome residents. This idea holds some support in the literature that has linked larger labor markets with better matching between job seekers and opportunities-or a reduction in skills mismatch (Büchel \& van Ham, 2003).

This study is not without limitations and results should be viewed in lieu of these. First, estimates are based on aggregate block group data and for the low- and high-income accessibility measures, we used householdbased data and not the actual working population within those categories. Second, we only consider auto-based accessibility. Although commutes to work by public transit in the Charlotte MSA is low, accounting for car availability or transit access could provide additional insight on transportation barriers to employment. Finally, as perhaps expected, our model fit for the employment-based models is relatively low suggesting that there are omitted factors that influence employment rates. As noted in the literature, there are other factors that are likely more important in explaining low employment rates such as lack of relevant skills, racial discrimination in hiring, or social networks, among others (Houston, 2005; Ihlanfeldt \& Sjoquist, 1990; Theys et al., 2019).

\section{Acknowledgments}

This research was supported by the Opportunity Research Fellowship Program, a grants program for UNC Charlotte faculty sponsored by the UNC Charlotte Urban Institute and the Charlotte Opportunity Insights Partnership and funded by The Gambrell Foundation.

\section{Conflict of Interests}

The authors declare no conflict of interests.

\section{References}

Allard, S. W., \& Danziger, S. (2002). Proximity and opportunity: How residence and race affect the employment of welfare recipients. Housing Policy Debate, 13(4), 675-700.

Anselin, L. (1988). Spatial econometrics: Methods and models. Dordrecht: Kluwer Academic Publishers.

Anselin, L. (1995). Local indicators of spatial associationLISA. Geographical analysis, 27(2), 93-115.

Åslund, O., Östh, J., \& Zenou, Y. (2010). How important is access to jobs? Old question-improved answer. Journal of Economic Geography, 10(3), 389-422.

Bailey, N., \& Minton, J. (2018). The suburbanisation of poverty in British cities, 2004-16: Extent, processes and nature. Urban Geography, 39(6), 892-915.

Bastiaanssen, J., Johnson, D., \& Lucas, K. (2020). Does transport help people to gain employment? A systematic review and meta-analysis of the empirical evidence. Transport Reviews, 40(5). https://doi.org/ 10.1080/01441647.2020.1747569

Boarnet, M. G., \& Wang, X. (2019). Urban spatial struc- ture and the potential for vehicle miles traveled reduction: The effects of accessibility to jobs within and beyond employment sub-centers. Annals of Regional Science, 62, 381-404.

Boisjoly, G., Moreno-Monroy, A. I., \& El-Geneidy, A. (2017). Informality and accessibility to jobs by public transit: Evidence from the São Paulo Metropolitan Region. Journal of Transport Geography, 64, 89-96.

Büchel, F., \& van Ham, M. (2003). Overeducation, regional labor markets, and spatial flexibility. Journal of Urban Economics, 53(3), 482-493.

Chemtob, D., \& Off, G. (2019, May 24). Charlotte jumps in rankings of largest U.S. cities, surpassing Indianapolis. Charlotte Observer. Retrieved from https://www.charlotteobserver.com/news/ business/biz-columns-blogs/development/ article230790609.html

Chetty, R., Hendren, N., Kline, P., \& Saez, E. (2014). Where is the land of opportunity? The geography of intergenerational mobility in the United States. The Quarterly Journal of Economics, 129(4), 1553-1623.

Cooke, T. J., \& Denton, C. (2015). The suburbanization of poverty? An alternative perspective. Urban Geography, 36(2), 300-313.

Delmelle, E. C. (2019). The increasing sociospatial fragmentation of urban America. Urban Science, 3(1). https://doi.org/10.3390/urbansci3010009

Delmelle, E. C., \& Thill, J. C. (2014). Mutual relationships in neighborhood socioeconomic change. Urban Geography, 35(8), 1215-1237.

e-CFR. (2019). Title 12: Banks and banking. Electronic Code of Federal Regulations. Retrieved from https://www.ecfr.gov/cgi-bin/text-idx?c=ecfr\&SID= 1551a215690d597cc181768b24f1d2b2\&rgn= div8\&view=text \&node=12:3.0.1.1.9.1.8.2\&idno $=12$

Ding, N., \& Bagchi-Sen, S. (2019). An analysis of commuting distance and job accessibility for residents in a U.S. legacy city. Annals of the American Association of Geographers, 109(5), 1560-1582.

Ehrenhalt, A. (2012). The great inversion and the future of the American city. New York, NY: Vintage.

Giuliano, G., Hou, Y., Kang, S., \& Shin, E.-J. (2015). Accessibility, location, and employment center growth. Los Angeles, CA: METRANS Transportation Center.

Glaeser, E. L., \& Kahn, M. E. (2001). Decentralized employment and the transformation of the American city (Working Paper No. 8117). Cambridge, MA: National Bureau of Economic Research.

Gobillon, L., Selod, H., \& Zenou, Y. (2007). The mechanisms of spatial mismatch. Urban Studies, 44(12), 2401-2427.

Graves, W., \& Kozar, J. (2015). Weak foundations: The failure of equilibrium-based population growth forecasts. Papers in Applied Geography, 1(2), 152-158.

Grengs, J. (2010). Job accessibility and the modal mismatch in Detroit. Journal of Transport Geography, 18(1), 42-54.

Heij, C., Boer, P., Franses, P. H., Kloek, T., \& Dijk, H. 
K. (2004). Econometric methods with applications in business and economics. New York, NY: Oxford University Press.

Hochstenbach, C., \& Musterd, S. (2018). Gentrification and the suburbanization of poverty: Changing urban geographies through boom and bust periods. Urban Geography, 39(1), 26-53.

Houston, D. (2005). Employability, skills mismatch and spatial mismatch in metropolitan labour markets. Urban Studies, 42(2), 221-243.

Hu, L. (2013). Changing job access of the poor: Effects of spatial and socioeconomic transformations in Chicago, 1990-2010. Urban Studies, 51(4), 675-692.

$\mathrm{Hu}$, L. (2015). Job accessibility of the poor in Los Angeles: Has suburbanization affected spatial mismatch? Journal of the American Planning Association, 81(1), 30-45.

Hu, L. (2017). Job accessibility and employment outcomes: which income groups benefit the most? Transportation, 44(6), 1421-1443.

Hu, L. (2019). Racial/ethnic differences in job accessibility effects: Explaining employment and commutes in the Los Angeles region. Transportation Research Part D: Transport and Environment, 76, 56-71.

Hu, L., \& Giuliano, G. (2014). Poverty concentration, job access, and employment outcomes. Journal of Urban Affairs.

Ihlanfeldt, K. R., \& Sjoquist, D. L. (1990). Job accessibility and racial differences in youth employment rates. The American Economic Review, 80(1), 267-276.

Immergluck, D. (1998). Job proximity and the urban employment problem: Do suitable nearby jobs improve neighbourhood employment rates? Urban Studies, 35(1), 7-23.

Jin, J., \& Paulsen, K. (2018). Does accessibility matter? Understanding the effect of job accessibility on labour market outcomes. Urban Studies, 55(1), 91-115.

Kain, J. F. (1968). Housing segregation, negro employment, and metropolitan decentralization. The Quarterly Journal of Economics, 82(2), 175-197.

Leading on Opportunity. (2020, March 24). We are agents of change. Leading on Opportunity. Retrieved from https://www.leadingonopportunity.org/about

Matas, A., Raymond, J., \& Roig, J. (2010). Job accessibility and female unemployment probability: The cases of Barcelona and Madrid. Urban Studies, 47(4), 769-787.

Merlin, L. A., \& Hu, L. (2017). Does competition matter in measures of job accessibility? Explaining employment in Los Angeles. Journal of Transport Geography, $64,77-88$.

Mouw, T. (2000). Job relocation and the racial gap in unemployment in Detroit and Chicago, 1980 to 1990. American Sociological Review, 65(5), 730-753.

Raphael, S., \& Stoll, M. A. (2010). Job sprawl and the suburbanization of poverty. Washington, DC: Metropolitan Policy Program at Brookings.

referenceUSA. (2020, March 24). Available databases. referenceUSA. Retrieved from http:// resource.referenceusa.com/available-databases

Sanchez, T. W. (1999). The connection between public transit and employment: The cases of Portland and Atlanta. Journal of the American Planning Association, 65(3), 284-296.

Sari, F. (2015). Public transit and labor market outcomes: Analysis of the connections in the French agglomeration of Bordeaux. Transportation Research Part A: Policy \& Practice, 78, 231-251.

Shen, Q. (1998). Location characteristics of innercity neighborhoods and employment accessibility of lowwage workers. Environment and Planning B, 25(3), 345-365.

Theys, T., Deschacht, N., Adriaenssens, S., \& Verhaest, D. (2019). The evolution of inter-regional spatial mismatch in the USA: The role of skills and spatial structure. Urban Studies, 56(13), 2654-2669.

United States Census Bureau. (2020, March 24). QuickFacts: Charlotte city, North Carolina. United States Census Bureau. Retrieved from https://www. census.gov/quickfacts/fact/table/charlottecity northcarolina/POP060210

Wang, F. (2003). Job proximity and accessibility for workers of various wage groups. Urban Geography, 24(3), 253-271.

\section{About the Authors}

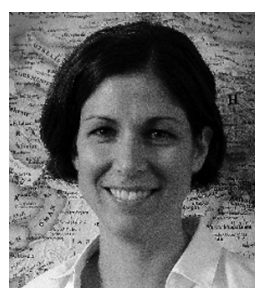

Elizabeth Delmelle is an Associate Professor of Geography at the University of North Carolina at Charlotte. Her research interests include geographic information science, urban and transportation geography.

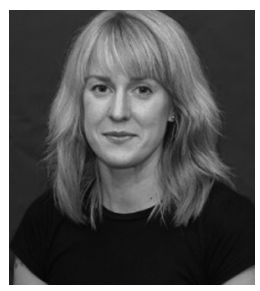

Isabelle Nilsson is an Assistant Professor of Geography and a core faculty in the Public Policy PhD program at the University of North Carolina at Charlotte. Her research is focused on urban transportation, housing, and local economic development issues. 


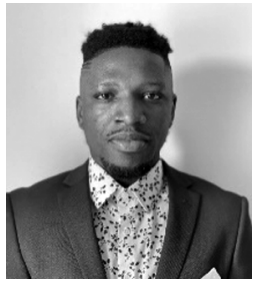

Providence Adu is a PhD student in Geography at the University of North Carolina at Charlotte. With a career background in city and regional planning, Providence's research interests are in housing policy, neighborhood change, and the application of geographic information science tools and machine learning methods in undertaking social science research. 